\title{
Pengaruh Pendidikan Kesehatan Terhadap Pelaksanaan Rentang Gerak Sendi Aktif Post Operasi \\ Pada Pasien Fraktur Ekstremitas di Ruang Bedah Trauma Center RSUP DR. M. Djamil Padang
}

\author{
Vivi Oktasari ${ }^{\mathrm{a}}$, Atih Rahayuningsih ${ }^{\mathrm{a}}$, Mira Susanti ${ }^{\mathrm{b}}$ \\ ${ }^{a}$ Fakultas Keperawatan Universitas Andalas ${ }^{\mathrm{b}}$ RSUP Dr. M. Djamil Padang \\ Korespodensi: Vivi Oktasari \\ E-mail: Oktasari.vivi@yahoo.com
}

\begin{abstract}
Mobilization is an important activity in the postoperative recovery to prevent complications, one of which contractures. Mobilization especially Range of Motion exercises can improve blood circulation which will speed healing and reduce pain. Immobilization in a long time because fracture will stimulate muscle artrofi skletal especially extremity which causes decreased muscle strength up to 5.5\% per day. To increase knowledge the fracture patients about exercises must be do post operative is through health education preoperative. The goal of this research was to know effect of health education to knowledge and implementation ROM active post ORIF in patients with fractures of the extremity. Design of reseach is quasy experiment with Post-test Only Control Group Design. Taking of sampling using accidental sampling technique, 20 patients with fractures of extremity plan ORIF surgery divided 2 groups: 10 patients to be experiment group and 10 patients to be control group. Analyzing the data is using independent $t$-test. The result showed that there were significant differences in knowledge scores $(p=0.000)$, scores of implementation $(p=0.000)$ among patients who received health education and patient are not given health education. it is suggested that nurses as service providers can implement health education preoperative especially range of motion exercises on the extremity fracture patients as a nursing intervention in a hospital to improve patients knowledge about postoperative exercises and motivate the patient to do range of motion exercises postoperative.
\end{abstract}

Key words: Health education, Knowledge, and Implementation ROM active

\begin{abstract}
Abstrak: Mobilisasi merupakan kegiatan yang penting dalam pemulihan post operasi untuk mencegah terjadinya komplikasi, salah satunya kontraktur. Mobilisasi khususnya latihan rentang gerak sendi akan meningkatkan sirkulasi darah untuk mempercepat penyembuhan dan mengurangi nyeri. Immobilisasi yang lama karena fraktur akan merangsang artrofi otot skletal terutama ekstremitas yang menyebabkan menurunnya kekuatan otot sampai 5,5\% perhari. Untuk meningkatkan pengetahuan pasien fraktur tentang latihan yang harus dilakukan post operasi adalah melalui pendidikan kesehatan pre operasi. Tujuan penelitian ini adalah untuk mengetahui pengaruh pendidikan kesehatn terhadap pengetahuan dan pelaksanaan rentang gerak sendi aktif post operasi ORIF pada pasien Fraktur Ekstremitas. Jenis penelitian ini menggunakan Quasi Eksperimen dengan pendekatan Post-test Only Control Group Design. Pengambilan sampel menggunakan teknik accidental sampling sebanyak 20 orang pasien fraktur ekstremitas dengan 10 orang pasien menjadi kelompok eksperimen dan 10 pasien menjadi kelompok kontrol. Analisa data menggunakan $t$ independent t-test. Hasil penelitian didapatkan bahwa ada perbedaan yang signifikan pada skor pengetahuan ( $\mathrm{p}=0,000)$, skor pelaksanaan $(\mathrm{p}=0,000)$ antara pasien yang diberikan pendidikan kesehatan dan pasien yang tidak diberikan pendidikan kesehatan. Disarankan perawat sebagai pemberi pelayanan dapat menerapkan pemberian pendidikan kesehatan preoperasi khususnya tentang latihan rentang gerak sendi pada pasien fraktur ekstremitas sebagai kegiatan intervensi keperawatan dirumah sakit untuk meningkatkan pengetahuan pasien dan memotivasi pasien dalam melakukan latihan rentang gerak sendi post operasi.
\end{abstract}

Kata kunci: Pendidikan kesehatan, Pengetahuan, Pelaksanaan rentang gerak sendi aktif 


\section{PENDAHULUAN}

Kecelakaan lalu lintas merupakan masalah kesehatan masyarakat diseluruh dunia, khususnya di negara berkembang. Menurut World Health Organization (WHO), kecelakaan lalu lintas menelan korban jiwa sekitar 2,4 juta jiwa manusia setiap tahunnya.Sementara di Indonesia, kecelakaan lalu lintas merupakan pembunuh nomor tiga setelah penyakit jantung dan stroke. Berdasarkan data dari Badan Pusat Statistik Republik Indonesia, tahun 2008 jumlah korban meninggal akibat kecelakaan 20.188 jiwa dari 59.164 kasus kecelakaan, tahun 2009 terdapat 19.979 jiwa dari 62.960 kasus kecelakaan dan tahun 2010 terdapat 19.873 jiwa dari 66.488 kasus kecelakaan (BPS RI, 2012).

Adapun kerugian-kerugian dari kecelakaan lalu lintas, selain kematian juga harta benda dan fisik. Kerusakan fisik yang paling sering terjadi dalam sebuah kecelakaan adalah fraktur. Fraktur adalah terputusnya kontinuitas tulang dan ditentukan sesuai jenis dan luasnya (Smeltzer, 2001).

Hasil survey tim Depkes RI (2007), dari 8 juta pasien fraktur didapatkan $25 \%$ pasien mengalami kematian, $45 \%$ mengalami kecacatan fisik, $15 \%$ mengalami stres psikologis karena cemas dan bahkan depresi, dan hanya $10 \%$ yang mengalami kesembuhan dengan baik. Berdasarkan data dinas Kesehatan Provinsi Sumatera Barat tahun 2009 didapatkan sekitar 2.700 orang mengalami insiden fraktur, $56 \%$ penderita mengalami kecacatan fisik, $24 \%$ mengalami kematian, $15 \%$ mengalami kesembuhan, dan 5\% mengalami gangguan psikologis atau depresi terhadap adanya kejadian fraktur (Dinkes Pemrov Sumbar, 2009). Prevalensi fraktur yang cukup tinggi yaitu insiden fraktur pada ekstremitas yakni sekitar $46,2 \%$ dari insiden kecelakaan yang terjadi (Depkes RI, 2009).

Penanganan fraktur terbagi menjadi dua jenis yaitu secara konservatif atau dilakukan tanpa pembedahan dan dilakukan dengan pembedahan. Penanganan fraktur dengan metode operatif adalah suatu bentuk operasi dengan pemasangan Open Reduction Internal Fixatie (ORIF) maupun dengan pemasangan Open Reduction External Fixatie (OREF). Prosedur pembedahan yang sering dilakukan pada pasien fraktur meliputi reduksi terbuka dengan fiksasi interna (ORIF) (Smeltzer, 2001). Keuntungan Fiksasi Interna ini tercapainya reposisi yang sempurna dan fiksasi yang kokoh dan mobilisasi dapat segera dilakukan ( Appley, 1995).

Perawatan segera setelah operasi, harus dilakukan mobilisasi agar fungsi kemandirian dapat dipertahankan. Manfaat dari mobilisasi yaitu untuk peningkatan sirkulasi darah yang dapat menyebabkan pengurangan rasa nyeri, mencegah tromboflebitis, memberi nutrisi untuk penyembuhan pada daerah luka, dan meningkatkan kelancaran fungsi ginjal (Long, 1988 dalam Ningsih 2011). Mobilisasi merupakan kegiatan yang penting dalam pemulihan post operasi untuk mencegah komplikasi lebih lanjut. Selama 24 sampai 48 jam pertama, perhatian ditujukan pada pemberian peredaan nyeri dan pencegahan komplikasi pasca operasi fraktur (Smeltzer, 2001).

Aktivitas sehari-hari membutuhkan kerja otot dan membantu mempertahankan tonus/kekuatan otot. Pada kondisi sakit dimana seseorang tidak mampu melakukan aktivitas karena keterbatasan gerak, maka kekuatan otot dapat dipertahankan melalui penggunaan otot yang terus-menerus, salah satunya melalui mobilisasi persendian dengan latihan rentang gerak sendi atau Range Of Motion (ROM) (Potter \& Perry, 2005).

Kemauan pasien dalam melaksanakan mobilisasi khususnya latihan rentang gerak sendi dipengaruhi oleh beberapafaktor, antara lain seperti usia, status perkembangan, pengalaman yang lalu atau riwayat pembedahan sebelumnya, gaya hidup, proses penyakit / injury, tingkat pendidikan dan pemberian informasi oleh petugas kesehatan (Kozier, 1995 dalam Ningsih 2011). Pemberian informasi oleh petugas kesehatan, khususnya perawat, 
salah satunya melalui pendidikan kesehatan.

Pendidikan kesehatan sebelum operasi tentang perilaku yang diharapkan dilakukan oleh klien pada pascaoperatif, yang diberikan melalui format yang sistematik dan terstruktur sesuai dengan prinsi-prinsip belajar-mengajar, mempunyai pengaruh yang positif bagi pemulihan klien. Apabila klien memahami alasan pentingnya latihan rentang gerak sendi untuk memulihkan kondisi pada pasca operasi dan klien mengetahui cara melakukannya dengan benar, maka komplikasi pada tahap pemulihan akan berkurang (Potter \& Perry, 2005).

Menurut penelitian yang dilakukan oleh Titi (2010) tentang pengaruh pendidikan kesehatan terhadap pengetahuan, sikap, dan tindakan pencegahan penularan TB Paru pada keluarga di Kecamatan Sitiung Kabupaten Dhamasraya, didapatkan bahwa pengetahuan responden tentang pencegahan penularan TB Paru sebelum diberikan pendidikan kesehatan berpengetahuan baik $(25,9 \%)$, dan setelah diberi pendidikan kesehatan pengetahuan responden meningkat menjadi (88,9\%). Hasil penelitian didapatkan bahwa ada pengaruh pendidikan kesehatan terhadap pengetahuan pasien TB Paru.

Selain itu, menurut penelitian yang dilakukan oleh Okwerita (2010) di Ruang Kebidanan RSUD Sungai Dareh tentang "Pengaruh penyuluhan terhadap pelaksanaan mobilisasi dini pada pasien paska bedah sesar" didapatkan bahwa pasien yang mendapatkan penyuluhan pre operatif sebagian besar melaksanakan mobilisasi dini dengan kategori baik (60\%), dan pasien yang tidak mendapatkan penyuluhan preoperatif sebagian besar melaksanakan mobilisasi dini dengan kategori sedang $(73,3 \%)$.

Rumah sakit M. Djamil Padang merupakan rumah sakit rujukan, dan banyak pasien yang menjalani pengobatan dengan kasus-kasus orthopedi. Berdasarkan data dari Rekam Medis di RSUP Dr. M.
Djamil Padang jumlah pasien fraktur pada ekstremitas tahun 2011 ada sebanyak 380 orang, dan tahun 2012 terdapat 405 kasus. Tahun 2011 jumlah pasien fraktur pada ekstremitas yang menjalani operasi ORIF adalah 165 pasien, dan tahun 2012 dari bulan Januari sampai September meningkat menjadi 178 pasien.

Berdasarkan studi pendahuluan yang dilakukan oleh peneliti di ruang Trauma Center RSUP Dr. M Djamil Padang pada tanggal 1 September 2012, dari 4 orang pasien fraktur pada ekstremitas post operasi ORIF yang diwawancarai, 2 orang post operasi hari kedua mengatakan nyeri sehingga pasien masih merasa takut untuk menggerakkan tungkainya,dan 2 orang pasien post operasi hari ketigamengeluh kaku dan bengkak disekitar area tungkai yang patah karena tidak ada ada dilatih untuk menggerakkan,dan mereka juga tidak tahu bahwa latihan rentang gerak sendi penting untuk pemulihan post operasi. Mereka mengatakan tidak ada diberi penyuluhan tentang latihan gerak sendi oleh perawat, dan perawat hanya memberitahu tentang persiapan menjelang operasi tapi sehari setelah operasi pasien ada disuruh gerak oleh perawat, tapi pasien tidak tahu gerakan seperti apa yang akan dilakukan. Pasien takut nanti patah pada tulangnya makin menjadi jika digerakkan, sehingga klien tidak ada melakukan gerakan pada tungkainya yang patah setelah operasi dan hanya berbaring di tempat tidur.

Sementara berdasarkan hasil wawancara tentang tingkat pengetahuan pasien tentang latihan rentang gerak sendi tanggal 1 September, dari 4 orang pasien post operasi, didapatkan 2 orang pasien tidak tahu tentang pengertian, kapan dilakukan, tujuan, cara gerakannnya latihan rentang gerak sendi, sementara 2 orang pasien tahu pengertian dan tujuannya, tapi tidak tahu kapan dilakukan, dan cara gerakannya seperti apa.

Berdasarkan hasil observasi yang dilakukan penulis tanggal 15 September 2012 di ruangan Trauma Center RSUP Dr. M Djamil Padang, jika ada pasien rencana operasi, perawat tidak ada melakukan 
penyuluhan tentang latihan rentang gerak sendi yang perlu dilakukan pasca operasi, perawat hanya menjelaskan pada pasien tentang persiapan operasi. Informasi yang didapat dari 2 orang perawat bahwa belum ada SOP (Standar Operasional Prosedur) tentang latihan rentang gerak sendi di ruangan.

\section{METODE}

Jenis penelitian adalah yang digunakan adalah Quasi Eksperimen dengan desain Post-test Only Control Group Design. Penelitian ini dilakukan di Ruang Bedah Trauma Center RSUP Dr. M Djamil Padang pada bulan Agustus 2012 sampai dengan April 2013, sedangkan pengumpulan data dilakukan pada tanggal 4 Februari 2013 sampai dengan 28 Februari 2013.
Populasi dalam penelitian ini adalah seluruh pasien fraktur ekstremitas yang akan melakukan operasi ORIF di Ruang Bedah Trauma Center RSUP Dr. M. Djamil Padang dengan jumlah rata-rata perbulan sebanyak 20 orang. Teknik pengambilan sampel yang digunakan dalam penelitian ini adalah dengan metode Accidental Sampling (Notoadmodjo, 2010). Jumlah sampel pada penelitian ini adalah 20 responden yang dibagi menjadi dua kelompok, yaitu 10 responden masuk kedalam kelompok intervensi (diberi pendidikan kesehatan) dan 10 responden masuk ke kelompok kontrol (tidak diberi pendidikan kesehatan), dengan kriteria antara lain: bersedia jadi responden, pasien fraktur ekstremitas yang rencana akan operasi ORIF dengan kesadaran penuh, mampu berkomunikasi dengan baik, dan tidak mengalami gangguan pendengaran.

\section{HASIL DAN PEMBAHASAN}

Tabel 1. Distribusi Pengetahuan Pasien Fraktur Ekstremitas Pre Operasi tentang Latihan Rentang Gerak Sendi pada Kelompok yang Diberi Pendidikan Kesehatan dan Kelompok yang Tidak Diberi Pendidikan Kesehatan di Ruang Bedah Trauma Center RSUP Dr. M. Djamil Padang Tahun 2013

\begin{tabular}{|l|c|c|c|c|c|c|}
\hline \multicolumn{1}{|c|}{ Kelompok } & Mean & Median & SD & Min & Max & 95\% CI \\
\hline $\begin{array}{l}\text { Kelompok yang diberi } \\
\text { penkes (Intervensi) }\end{array}$ & 9,90 & 9,50 & 1,595 & 8 & 12 & $8,76-11,04$ \\
\hline $\begin{array}{l}\text { Kelompok yang tidak } \\
\text { diberi penkes (Kontrol) }\end{array}$ & 3,30 & 3,00 & 1,337 & 2 & 6 & $2,34-4,26$ \\
\hline
\end{tabular}

Tabel 2. Distribusi Pelaksanaan Rentang Gerak Sendi Aktif Post Operasi ORIF pada Pasien Fraktur Ekstremitas pada Kelompok yang Diberi Pendidikan Kesehatan dan Kelompok yang Tidak Diberi Pendidikan Kesehatan di Ruang Bedah Trauma Center RSUP Dr. M. Djamil Padang Tahun 2013

\begin{tabular}{|l|c|c|c|c|c|c|}
\hline \multicolumn{1}{|c|}{ Kelompok } & Mean & Median & SD & Min & Max & 95\% CI \\
\hline $\begin{array}{l}\text { Kelompok yang diberi } \\
\text { penkes (Intervensi) }\end{array}$ & 28,40 & 28,50 & 2,914 & 23 & 32 & $26,32-30,48$ \\
\hline $\begin{array}{l}\text { Kelompok yang tidak } \\
\text { diberi penkes (Kontrol) }\end{array}$ & 3,30 & 3,00 & 2,669 & 0 & 7 & $1,39-5,21$ \\
\hline
\end{tabular}


Tabel 3. Pengaruh Pendidikan Kesehatan Terhadap Pengetahuan dan Pelaksanaan Rentang Gerak Sendi Aktif Post Operasi ORIF Pada Pasien Fraktur Ekstremitas di Ruang Bedah Trauma Center RSUP Dr. M. Djamil Padang Tahun 2013

\begin{tabular}{|c|c|c|c|c|c|c|c|}
\hline & Kelompok & Mean & SD & Min & Max & $p$ & $\mathbf{N}$ \\
\hline \multirow{2}{*}{$\begin{array}{c}\text { Skor } \\
\text { Pengetahuan }\end{array}$} & $\begin{array}{l}\text { Kelompok yang diberi } \\
\text { penkes (Intervensi) }\end{array}$ & 9,90 & 1,595 & 8 & 12 & \multirow[b]{2}{*}{0,000} & \multirow[b]{2}{*}{20} \\
\hline & $\begin{array}{l}\text { Kelompok yang tidak } \\
\text { diberi penkes (Kontrol) }\end{array}$ & 3,30 & 1,337 & 2 & 6 & & \\
\hline \multirow{2}{*}{$\begin{array}{c}\text { Skor } \\
\text { Pelaksanaan } \\
\text { rentang gerak } \\
\text { sendi aktif }\end{array}$} & $\begin{array}{l}\text { Kelompok yang diberi } \\
\text { penkes (Intervensi) }\end{array}$ & 28,40 & 2,914 & 23 & 32 & \multirow[b]{2}{*}{0,000} & \multirow[b]{2}{*}{20} \\
\hline & $\begin{array}{l}\text { Kelompok yang tidak } \\
\text { diberi penkes (Kontrol) }\end{array}$ & 3,30 & 2,669 & 0 & 7 & & \\
\hline
\end{tabular}

1. Pengaruh Pendidikan Kesehatan terhadap Pengetahuan Responden tentang Latihan Rentang Gerak Sendi di Ruang Bedah Trauma Center RSUP Dr. M. Djamil Padang Tahun 2013

Berdasarkan hasil penelitian yang telah dilakukan didapatkan rata-rata skor pengetahuan responden tentang latihan rentang gerak sendi pada kelompok yang diberi pendidikan kesehatan adalah 9,90 dengan standar deviasi 1,595, sedangkan rata-rata skor pengetahuan responden pada kelompok yang tidak diberikan pendidikan kesehatan adalah 3,30 dengan standar deviasi 1,337. Berdasarkan hasil uji statistik dengan menggunakan uji independent $t$ test didapatkan nilai $\mathrm{p}=$ $0,000$ ( $\mathrm{p}<0,05)$, ini artinya terdapat pengaruh yang bermakna antara pendidikan kesehatan terhadap pengetahuan responden tentang latihan rentang gerak sendi pada pasien fraktur ekstremitas.

Hal ini sesuai dengan penelitian yang dilakukan oleh Titi (2010) tentang pengaruh pendidikan kesehatan terhadap pengetahuan, sikap, dan tindakan pencegahan penularan TB Paru pada keluarga di Kecamatan Sitiung Kabupaten Dhamasraya, dimana dari hasil penelitian terhadap 27 responden TB Paru didapatkan bahwa sebelum diberi pendidikan kesehatan (74\%) responden berpengetahuan kurang baik, dan setelah diberi pendidikan kesehatan $(88,9 \%)$ memiliki pengetahuan baik tentang pencegahan penularan TB Paru. Hasil penelitian yang diperoleh membuktikan bahwa ada pengaruh pendidikan kesehatan terhadap pengetahuan pasien TB Paru.

Pendidikan kesehatan pre operasi didefinisikan sebagai tindakan suportif dan pendidikan yang dilakukan perawat untuk membantu pasien bedah dalam meningkatkan kesehatannya sendiri sebelum dan sesudah pembedahan (Smith et al; Carpenito, 1995). Berbagai latihan sangat diperlukan pasien sebelum operasi, hal ini sangat penting sebagai persiapan pasien dalam menghadapi kondisi pasca operasi. Dengan memberikan pendidikan sebelum operasi tentang latihan rentang gerak sendi, maka pasien akan tahu tentang latihan untuk memulihkan kondisi post operasi ORIF, dan kemungkinan komplikasi yang akan terjadi post operasi bisa dihindari.

Pendidikan kesehatan sebelum operasi tentang perilaku yang diharapkan dilakukan oleh klien pada pascaoperatif, yang diberikan melalui format yang sistematik dan terstruktur sesuai dengan prinsi-prinsip belajar-mengajar, 
mempunyai pengaruh yang positif bagi pemulihan klien. Apabila klien memahami alasan pentingnya latihan rentang gerak sendi untuk memulihkan kondisi pada pasca operasi dan klien mengetahui cara melakukannya dengan benar, maka komplikasi pada tahap pemulihan akan berkurang (Potter \& Perry, 2005).

Salah satu faktor yang dapat mempengaruhi pengetahuan seseorang adalah pendidikan. Hasil penelitian diatas juga didukung oleh tingkat pendidikan responden, dimana pada kelompok intervensi 6 responden $(60 \%)$ mempunyai pendidikan menengah keatas, sedangkan 8 responden $(80 \%)$ pada kelompok kontrol masih berpendidikan dasar. Hal ini sesuai dengan pendapat Maulana (2009) dalam Titi (2010) bahwa tingkat pengetahuan seseorang dipengaruhi oleh pendidikan, dimana semakin tinggi tingkat pendidikan seseorang maka akan semakin tinggi pengetahuan yang dimiliki, karena seseorang yang tingkat pendidikannya lebih tinggi akan lebih mudah menerima dan memahami informasi yang diberikan.

Faktor lain yang dapat mempengaruhi tingkat pengetahuan seseorang adalah usia. Dilihat dari karakteristik usia responden pada kelompok eksperimen, lebih dari separuh responden $(70 \%)$ berada pada rentang usia dewasa, begitu juga dengan kelompok kontrol hampir seluruh responden $(90 \%)$ berada pada rentang usia dewasa. Singgih (1998) mengemukakan bahwa makin tua umur seseorang maka proses-proses perkembangan mentalnya bertambah baik, selain itu Ahmadi (2001) juga mengemukakan bahwa memang daya ingat seseorang itu salah satunya dipengaruhi oleh usia.

Meningkatnya skor pengetahuan responden juga dipengaruhi oleh faktorfaktor media dari edukasi personal, dimana dalam memberikan pendidikan kesehatan secara individual peneliti menggunakan lembar balik yang dapat menarik perhatian responden karena dapat menampilkan warna beserta gambar. Dalam hal ini peneliti juga memberikan leaflet yang disertai gambar tentang langkah-langkah gerakan rentang gerak sendi untuk responden yang bisa dibaca sebagai penambah wawasan. Sesuai dengan pendapat Notoadmodjo (2007) media edukasi kesehatan adalah alat-alat yang merupakan saluran (channel) untuk menyampaikan informasi kesehatan. Sehingga indra yang sering terlibat adalah pendengaran, penglihatan dan perabaan, tetapi dari ketiganya indra penglihatan adalah yang paling dominan. Notoatmodjo (2005) mengatakan media yang baik berfungsi untuk membantu dalam proses pendidikan suatu pengajaran sehingga pesan kesehatan dapat disampaikan dengan jelas dan tepat.

Berdasarkan pendapat diatas, maka peneliti berasumsi bahwa pendidikan kesehatan pre operasi merupakan salah satu cara yang efektif digunakan untuk meningkatkan pengetahuan pasien fraktur ekstremitas tentang latihan yang harus dilakukan post operasi ORIF. Seseorang yang mendapatkan pendidikan kesehatan sebelum operasi, maka mereka akan mendapatkan informasi yang akan meningkatkan pengetahuan, sebaliknya berbeda dengan orang yang tidak mendapatkan pendidikan kesehatan, dimana pengetahuan mereka cenderung tidak bertambah karena tidak mendapat informasi.

2. Pengaruh Pendidikan Kesehatan Terhadap Pelaksanaan Rentang Gerak Sendi Aktif Post Operasi ORIF di Ruang Bedah Trauma Center RSUP Dr. M. Djamil Padang Tahun 2013

Hasil penelitian yang telah dilakukan tentang pelaksanaan rentang gerak sendi aktif post operasi ORIF didapatkan ratarata skor pelaksanaan pada kelompok yang diberikan pendidikan kesehatan adalah 28,40 , sedangkan rata-rata pada kelompok kontrol yang tidak diberikan pendidikan kesehatan adalah 3,30. Hasil uji statistik dengan menggunakan uji independent $t$ test didapatkan nilai $\mathrm{p}=0,000(\mathrm{p}<0,05)$, 
maka dapat disimpulkan bahwa terdapat pengaruh pendidikan kesehatan terhadap pelaksanaan rentang gerak sendi aktif post operasi ORIF pada pasien fraktur ekstremitas.

Berdasarkan penelitian yang dilakukan oleh Okwerita (2010) di Ruang Kebidanan RSUD Sungai Dareh tentang "Pengaruh penyuluhan terhadap pelaksanaan mobilisasi dini pada pasien paska bedah sesar " didapatkan bahwa pasien yang mendapatkan penyuluhan preoperative melaksanakan mobilisasi dini dengan kategori baik (60\%), dan pasien yang tidak mendapatkan penyuluhan preoperatif melaksanakan mobilisasi dini dengan kategori sedang $(73,3 \%)$. Hasil penelitian didapatkan bahwa pendidikan kesehatan berpengaruh terhadap pelaksanaan mobilisasi dini paska bedah sesar.

Wood (1926) dalam Mubarak (2006) mengemukakan bahwa pendidikan kesehatan adalah sebagai sekumpulan pengalaman yang mendukung kebiasaan, sikap dan tindakan pengetahuan yang berhubungan dengan kesehatan perorangan, masyarakat dan bangsa. Salah satu upaya yang dilakukan untuk meningkatkan derajat kesehatan masyarakat adalah melalui pendidikan kesehatan.

Berdasarkan analisa peneliti, dari hasil penelitian tampak bahwa pada kelompok yang diberikan pendidikan kesehatan sebagian besar responden sudah mengikuti pelaksanaan rentang gerak sendi aktif, dimana skor rata-rata adalah 28,40, lebih tinggi dibandingkan dengan rata-rata kelompok yang tidak diberikan pendidikan kesehatan yaitu 3,30. Hal ini juga diperkuat oleh rata-rata skor pengetahuan responden pada kelompok intervensi lebih tinggi dibandingkan kelompok kontrol, sehingga dengan tingginya pengetahuan maka tingkat kesadaran responden untuk melaksanakan latihan rentang gerak sendi juga lebih besar, selain itu juga dapat dilihat dari pendidikan responden pada kelompok intervensi lebih dari separuh $(60 \%)$ responden berpendidikan menengah keatas sehingga responden semakin mudah memahami tentang pentingnya melakukan latihan rentang gerak sendi post operasi.

Menurut Notoatmodjo (2003) tingkat pendidikan mempengaruhi perilaku dan menghasilkan banyak perubahan, khususnya pengetahuan dibidang kesehatan. Semakin tinggi tingkat pendidikan formal akan semakin mudah seseorang menyerap informasi dan semakin tinggi pula kesadaran untuk berprilaku hidup sehat.

Potter \& Perry (2005) mengatakan bahwa latihan rentang gerak sendi merupakan hal yang sangat penting bagi pemulihan post operasi, khususnya pasien fraktur yang akan mempercepat proses penyembuhan. Pendidikan preoperasi tentang latihan rentang gerak sendi dapat memberikan pemahaman yang baik pada pasien tentang latihan post operasi. Perilaku latihan post operasi yang baik dapat terjadi karena suatu proses pembelajaran melalui edukasi preoperasi, baik berupa penambahan pengetahuan dan juga penambahan keterampilan.

Pendidikan kesehatan adalah proses yang menjembatani kesenjangan antara informasi kesehatan dan praktek kesehatan, yang memotivasi seseorang untuk memperoleh informasi dan berbuat sesuatu sehingga menjadi lebih sehat dan membentuk kebiasaan yang menguntungkan kesehatan. Pengetahuan sangat erat kaitannya dengan motivasi, dengan seseorang mengetahui tentang sesuatu hal, maka ia akan termotivasi untuk mencari tahu lebih rinci lagi tentang hal tersebut yang akhirnya akan mengubah perilaku seseorang. Umumnya motivasi akan meningkat setelah mengenal kebutuhannya dan merasa yakin kebutuhan tersebut dapat terpenuhi (Suliha, 2002).

Berdasarkan pendapat diatas, maka peneliti berasumsi bahwa pendidikan kesehatan pre operasi akan meningkatkan pengetahuan yang seseorang mengenai latihan post operasi, dengan pengetahuan tersebut maka seseorang akan cendrung 
untuk merubah perilaku demi meningkatkan kesehatannya. Hal ini juga tampak dari hasil penelitian diatas dimana kelompok responden yang diberi pendidikan kesehatan sebelum operasi rata-rata melaksanakan rentang gerak sendi aktif post operasi, dan berbeda dengan kelompok yang tidak diberi pendidikan kesehatan, dimana karena ketidaktahuannya mereka tidak melakukan latihan gerak sendi post operasi. Hal ini membuktikan bahwa pendidikan kesehatan mempunyai pengaruh terhadap pelaksanaan rentang gerak sendi aktif post operasi ORIF.

\section{KESIMPULAN DAN SARAN}

Dari hasil penelitian yang telah dilakukan dapat disimpulkan bahwa:

1. Rata-rata skor pengetahuan pasien fraktur ekstremitas yang diberikan pendidikan kesehatan adalah 9,90 (SD $\pm 1,595)$, sedangkan rata-rata skor pengetahuan pasien yang tidak diberikan pendidikan kesehatan adalah 3,30 ( $\mathrm{SD} \pm 1,337$ ).

2. Rata-rata skor pelaksanaan rentang gerak sendi aktif post operasi ORIF pada pasien fraktur ekstremitas yang diberikan pendidikan kesehatan adalah $28,40$ (SD $\pm 2,914)$, sedangkan rata-rata skor pelaksanaan rentang gerak sendi aktif pada pasien yang tidak diberikan pendidikan kesehatan adalah 3,30 (SD $\pm 2,669)$.

3. Terdapat pengaruh pendidikan kesehatan terhadap pengetahuan pasien fraktur ekstremitas tentang latihan rentang gerak sendi di Ruang Bedah Trauma Center RSUP Dr. M. Djamil Padang Tahun 2013 ( $\mathrm{p}=0,000)$.

4. Terdapat pengaruh pendidikan kesehatan terhadap pelaksanaan rentang gerak sendi aktif post operasi ORIF pada pasien fraktur ekstremitas di Ruang Bedah Trauma Center RSUP Dr. M. Djamil Padang Tahun 2013 $(\mathrm{p}=0,000)$.

Bagi pimpinan rumah sakit disarankan agar pendidikan kesehatan preoperasi dapat diterapkan menjadi salah satu Standar Operasional Prosedur (SOP), sehingga komplikasi post operasi dapat dihindari. Kemudian memberikan pelatihan dan pembinaan kepada perawat agar pelaksanaan penyuluhan tentang latihan rentang gerak sendi pada pasien pasien fraktur ekstremitas dapat terlaksana dengan baik.

\section{DAFTAR PUSTAKA}

Apley. A \& Solomon, L. (1995). Buku Ajar Ortopedi dan Fraktur Sistem Apley (Edisi 7). Jakarta : Widya Medika.

BPS RI. (2012). Jumlah kecelakaan, koban mati, luka berat, luka ringan, dan kerugian materi yang diderita tahun 1992-2010.

Notoatmodjo. (2003). Pendidikan dan Perilaku Kesehatan. Jakarta : Rineka Cipta.

(2005). Promosi Kesehatan Teori dan Aplikasi. Jakarta : Rineka Cipta.

(2007). Promosi Kesehatan dan Ilmu Perilaku. Jakarta : Rineka Cipta.

(2010). Metodologi Penelitian Kesehatan. Jakarta : Rineka Cipta.

Ningsih, A.R. (2011). Faktor-faktor yang mempengaruhi perawat dalam pelaksanaan pennyuluhan mobilisasi dini pada pasien pre operasi di Irna Bedah RSUP Dr. M Djamil Padang.

Kozier. (1995). Fundamental Of Nursing Concept, Process And Practice. Jakarta : EGC.

Okwerita. (2010). Pengaruh penyuluhan terhadap pelaksanaan mobilisasi dini pada pasien paska bedah sesar di Ruang Kebidanan RSUD Sungai Dareh. 
Potter \& Perry. (2005). Buku Ajar Fundamental Keperawatan : Konsep, Proses, dan Praktik (Edisi 4). Jakarta : EGC.

Smeltzer, S \&Brenda G. Bare. (2001). Buku Ajar Keperawatan Medikal Bedah Brunner \& Suddarth (Edisi 8). Jakarta : EGC.
Suliha Uha. (2002). Pendidikan kesehatan dalam keperawatan. Jakarta : EGC.

Titi. (2010). Pengaruh pendidikan kesehatan terhadap pengetahuan, sikap, dan tindakan pencegahan penularan TB Paru pada keluarga di Kecamatan Sitiung Kabupaten Dhamasraya. 